\title{
Teste de germinação em sementes de Cucumis metuliferus E. Mey
}

\author{
Germination test in Cucumis metuliferus E. Mey seeds
}

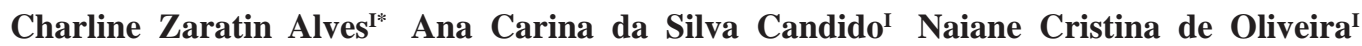 Flávia Mendes dos Santos Lourenço ${ }^{I}$}

\section{RESUMO}

O kino (Cucumis metuliferus E. Mey) é uma olerícola de ampla distribuição geográfica, com aumento significativo em relação à comercialização no mundo inteiro, devido não só à sua vida útil ser muito longa em temperatura ambiente, como também pela constante busca do mercado consumidor por produtos exóticos. Assim, a demanda e a comercialização de suas sementes estão aumentando, gerando a necessidade do estabelecimento de padrões estaduais e federais e do desenvolvimento de metodologias adequadas para a avaliação da qualidade delas. Dessa maneira, o objetivo deste trabalho foi determinar a metodologia quanto ao substrato, temperatura e tempo de contagem para o teste de germinação em sementes de kino. As avaliações constaram de quatro substratos: rolo de papel, sobre papel, entre areia e sobre areia e quatro temperaturas: 20,25 e $30^{\circ} \mathrm{C}$ constantes e 20$30^{\circ} \mathrm{C}$ alternada. $\mathrm{O}$ efeito dos substratos e temperaturas sobre o desempenho das sementes foi avaliado pelo teste de germinação, índice de velocidade e tempo médio de germinação. O experimento foi instalado em delineamento inteiramente ao acaso, com os tratamentos distribuídos em esquema fatorial $4 \times 4$ (substratos $x$ temperaturas), com quatro repetições. O teste de germinação em sementes de kino deve ser realizado no rolo de papel, à temperatura constante de $25^{\circ} \mathrm{C}$ ou alternada de $20-30^{\circ} \mathrm{C}$, com a contagem inicial e final, no quinto e décimo dia, respectivamente.

Palavras-chave: kino, substrato, temperatura.

\section{ABSTRACT}

The kiwano (Cucumis metuliferus E. Mey) is a cop of wide geographical distribution, with a significant increase in relation to marketing worldwide due not only to his life being too long at room temperature, as well as to the constant search market consumer for exotic products. Thus, demand and marketing of its seeds are increasing, creating the need for the establishment of state and federal standards and the development of appropriate methodologies for evaluating the quality of them. Thus, the objective of this study was to determine the methodology for the substrate, temperature and time count for the germination test on Kiwano seeds. The evaluations consisted of four substrates: paper roll, on paper, in sand and on sand at four temperatures: $20,25 \mathrm{e} 30^{\circ} \mathrm{C}$ constant and $20-30^{\circ} \mathrm{C}$ alternating. The effect of substrate and temperature on seed performance was evaluated using germination, speed index and mean germination time. The experiment was conducted in a completely randomized design with treatments arranged in a factorial $4 \times 4$ (substrates $x$ temperatures) with four replications. The test germination in seeds of kiwano should be done on the paper roll at constant temperature of $25^{\circ} \mathrm{C}$ or alternating $20-30^{\circ} \mathrm{C}$, with counting starting and ending in the fifth and tenth day, respectively.

Key words: kiwano, substrate, temperature.

\section{INTRODUÇÃO}

Pertencente à família das cucurbitáceas, o kino ou kiwano (Cucumis metuliferus E. Mey), como é conhecido no Brasil e no mundo, respectivamente, é originário das regiões Sul e Central do continente africano (BENZIONI, 1997). Além de ser uma planta ornamental, seu fruto, rico em potássio e pobre em sódio, é recomendado como diurético e para pessoas diabéticas, sendo também usado in natura no preparo de refrescos, drinques, saladas, além de ingrediente em geleia, cozidos de carne e peixe. Suas sementes são vermífugas e suas folhas podem ser consumidas após o cozimento (FUNDACIÓN EROSKI, 2012). Os frutos, ainda jovens, são de cor verde-amarelada e, quando maduros, apresentam cor vermelhoalaranjada, possuindo forma elipsoide, protuberâncias parecidas com espinhos em sua epiderme, mesocarpo

IDepartamento de Agronomia, Universidade Federal de Mato Grosso do Sul (UFMS), 79560-000, Chapadão do Sul, MS, Brasil. E-mail: charline.alves@ufms.br.*Autor para correspondência. 
de coloração verde-claro, com sementes envoltas numa substância mucilaginosa (BENZIONI, 1997).

Nos últimos anos, principalmente nos Estados Unidos, Europa e Japão, houve aumento significativo na comercialização de kino, devido não só à busca do mercado consumidor por produtos exóticos, como também pela sua longa vida útil em temperatura ambiente (MARSH, 1993), gerando assim demanda por sementes dessa espécie, o que leva à necessidade do estabelecimento de padrões estaduais e federais e desenvolvimento de metodologias adequadas para avaliação da qualidade das sementes.

O teste de germinação é o principal parâmetro utilizado para avaliação da qualidade fisiológica das sementes, permitindo conhecer o potencial de germinação de um lote em condições favoráveis (CARVALHO \& NAKAGAWA, 2012) e, para isso, esse teste deve seguir um procedimento padrão, recomendado pelas RAS - Regras para Análise de Sementes (BRASIL, 2009) - publicação oficial que normatiza a análise de sementes, para que a germinação ocorra nas condições ótimas de cada espécie. No entanto, para as sementes de kino, a metodologia do teste ainda não foi estabelecida e, entre os procedimentos, destacam-se os referentes ao substrato e à temperatura.

O substrato utilizado no teste de germinação desempenha grande influência, uma vez que fatores como estrutura, aeração, capacidade de retenção de água e grau de infestação de patógenos podem variar de acordo com o tipo de material utilizado (POPINIGIS, 1985). De acordo com BRASIL (2009), na escolha do substrato, deve-se levar em consideração o tamanho da semente, exigência em relação à quantidade de água, sensibilidade ou não à luz e a facilidade que este oferece para a realização das contagens e avaliação das plântulas.

A temperatura influencia a germinação, agindo sobre a velocidade de absorção de água e também nas reações bioquímicas que determinam todo o processo, afetando o total e a velocidade de germinação (BEWLEY \& BLACK, 1994), sendo que esta aumenta com as temperaturas máximas, e diminui com as mínimas. No entanto, em temperaturas máximas, somente as sementes mais vigorosas conseguem germinar, ocorrendo redução na porcentagem de germinação; já as temperaturas mínimas alteram a uniformidade de emergência, possivelmente pelo maior tempo de exposição das sementes aos patógenos (CARVALHO \& NAKAGAWA, 2012). As temperaturas constantes favorecem a germinação de algumas espécies, como Brassica campestris a $30^{\circ} \mathrm{C}$ (DE LA ROSA-IBARRA et al., 2000), enquanto outras são favorecidas por temperaturas alternadas, conforme verificado em sementes de Raphanus sativus L. (NERY et al., 2009).

Apesar de o kino ainda ser pouco conhecido no Brasil, devido ao seu elevado valor no comércio local, não existem trabalhos brasileiros na literatura a respeito dessa espécie, aliado à possibilidade de grande expansão da cultura devido às condições climáticas favoráveis, como também ao elevado mercado consumidor. Assim, objetivou-se, neste trabalho, determinar a metodologia quanto ao substrato, temperatura e tempo de contagem para o teste de germinação em sementes de kino.

\section{MATERIAL E MÉTODOS}

O trabalho foi conduzido no Laboratório de Tecnologia de Sementes da Universidade Federal de Mato Grosso do Sul, Campus de Chapadão do Sul (CPCS/UFMS). As sementes de kino provenientes de frutos maduros, obtidos comercialmente, foram retiradas manualmente, juntamente com a mucilagem, e posteriormente passaram por lavagem em água corrente sobre peneira de malha fina, sendo em seguida deixadas para secar por três dias em temperatura ambiente.

Os tratamentos consistiram de quatro substratos: rolo de papel, sobre papel, entre areia e sobre areia e quatro temperaturas: 20,25 e $30^{\circ} \mathrm{C}$ constantes e $20-30^{\circ} \mathrm{C}$ alternada. Para o substrato rolo de papel, quatro subamostras de 50 sementes foram distribuídas sobre duas folhas de papel toalha germitest, umedecidas com quantidade de água equivalente a 2,5 vezes o peso do papel seco, coberto com uma terceira folha. Logo após, foram confeccionados em forma de rolos que permaneceram acondicionados dentro de sacos plásticos de 0,033mm de espessura, para evitar a desidratação, e mantidos em germinador. Para o substrato sobre papel, quatro subamostras de 25 sementes foram colocadas em caixas plásticas do tipo gerbox com duas folhas de papel germitest, umedecido com água destilada na proporção de 2,5 vezes o peso do papel seco.

Para que a distância entre as sementes nos substratos fosse a mesma, a germinação em areia foi conduzida com quatro subamostras de 25 sementes em caixas plásticas do tipo gerbox, por ser similar em comprimento e largura das dimensões do substrato sobre papel. No substrato entre areia, as sementes foram dispostas a uma profundidade de $5 \mathrm{~mm}$ e, sobre 
areia, depositadas sobre o referido substrato, sendo que o umedecimento da areia em ambos foi feito com água destilada até atingir 60\% da capacidade de campo (BRASIL, 2009).

O efeito dos substratos e temperaturas sobre o desempenho das sementes foi avaliado pelo teste de germinação, sendo contadas diariamente as sementes que apresentavam emissão da raiz primária maior que $2 \mathrm{~mm}$ de comprimento, e o período de duração do teste foi determinado como sendo o número de dias a partir do qual houve estabilização da germinação. Também foi calculado o índice de velocidade de germinação, de acordo com a fórmula proposta por MAGUIRE (1962), e o tempo médio de germinação, seguindo a fórmula sugerida por LABOURIAU (1983).

$\mathrm{O}$ experimento foi instalado em delineamento inteiramente ao acaso, com os tratamentos distribuídos em esquema fatorial $4 \times 4$ (substratos x temperaturas), com quatro repetições. As médias foram comparadas pelo teste de Tukey a $5 \%$ de probabilidade.

\section{RESULTADOS E DISCUSSÃO}

Pelos resultados da tabela 1 , verificou-se interação significativa entre substratos e temperaturas para a porcentagem e índice de velocidade de germinação, no qual se observou que, na temperatura de $20^{\circ} \mathrm{C}$, o melhor substrato foi o rolo de papel, pois proporcionou maiores valores de germinação. Nas temperaturas de 25 e $20-30^{\circ} \mathrm{C}$, não houve diferença significativa entre os substratos, com exceção entre areia, que proporcionou uma redução na porcentagem de germinação em ambas as temperaturas; a $30^{\circ} \mathrm{C}$, o substrato sobre areia foi o mais adequado, não diferindo estatisticamente do rolo de papel.

Quando se utilizou o substrato rolo de papel, os tratamentos que permaneceram nas temperaturas de 20,25 e $20-30^{\circ} \mathrm{C}$ não diferiram estatisticamente entre si, sendo que a $30^{\circ} \mathrm{C}$ houve redução da porcentagem de germinação (Tabela 1); a temperatura de $25^{\circ} \mathrm{C}$ foi a mais adequada no substrato sobre papel, não diferindo da temperatura alternada de $20-30^{\circ} \mathrm{C}$; verificando-se mais uma vez redução na porcentagem de germinação na temperatura de $30^{\circ} \mathrm{C}$. A germinação de sementes de kino, semeadas em placas de Petri contendo algodão umedecido como substrato, foi prejudicada nas temperaturas acima de $35^{\circ} \mathrm{C}$ (BENZIONI et al., 1991).

No substrato entre areia, não houve diferença entre as temperaturas testadas, observandose, porém, baixa porcentagem de germinação, comparada aos demais tratamentos, fato este que corrobora os resultados obtidos por ALVES et al. (2011) em sementes de pitaia. No substrato sobre areia, não houve diferença entre as temperaturas, com exceção da mais baixa $\left(20^{\circ} \mathrm{C}\right)$, pois ocorreu uma drástica redução na porcentagem de germinação.

No teste de germinação, a área de contato do substrato umedecido com a semente é importante e pode ser crítica, tanto para a germinação total, como também para a velocidade de germinação. De acordo com CARNEIRO \& GUEDES (1992) quanto maior o contato das sementes com o substrato, menor o tempo necessário para que a germinação total seja alcançada.

Tabela 1 - Dados médios obtidos para germinação (\%) e índice de velocidade de germinação de sementes de kino em função de diferentes substratos e temperaturas.

\begin{tabular}{|c|c|c|c|c|}
\hline \multirow{2}{*}{ Substratos } & \multirow[b]{2}{*}{20} & \multirow[b]{2}{*}{25} & & \multirow[b]{2}{*}{$20-30$} \\
\hline & & & 30 & \\
\hline $\mathrm{RP}$ & 61,50 а $\mathrm{AB}^{*}$ & 81,50 а A & $52.50 \mathrm{ab} B$ & 82,50 а $A$ \\
\hline SP & $37,00 \mathrm{ab} B C$ & 88,00 a $A$ & 24,00 bc $C$ & 64,00 a $\mathrm{AB}$ \\
\hline EA & $23,00 \mathrm{~b} \mathrm{~A}$ & $12,00 \mathrm{~b} \mathrm{~A}$ & 15,00 с A & $30,00 \mathrm{~b} \mathrm{~A}$ \\
\hline \multirow[t]{2}{*}{ SA } & $22,00 \mathrm{~b} \mathrm{~B}$ & 82,00 a $\mathrm{A}$ & 56,00 a $A$ & 63,00 a $A$ \\
\hline & & ---Índice c & rminação------ & ---------- \\
\hline $\mathrm{RP}$ & 10,00 а $A^{*}$ & 12,25 a A & 6,00 a B & 13,25 a $\mathrm{A}$ \\
\hline SP & $4,50 \mathrm{~b} B C$ & 9,75 a $A$ & 2,00 bc $C$ & 6,75 bc $\mathrm{AB}$ \\
\hline EA & 3,75 b A & 1,75 b A & 1,50 с A & 3,25 с A \\
\hline SA & 3,50 b C & 11,50 a $\mathrm{A}$ & 5,25 ab BC & 8,75 b AB \\
\hline
\end{tabular}

*Médias seguidas de mesma letra maiúscula na linha e minúscula na coluna, dentro de cada teste, não diferem entre si pelo teste de Tukey a $5 \%$ de probabilidade. RP - rolo de papel; SP - sobre papel; EA - entre areia; SA - sobre areia. 
Quando a área de contato com as sementes é pequena, a velocidade de absorção de água pode ser menor do que a taxa de perda de água (OLIVEIRA JUNIOR \& DELISTOIANOV, 1996).

$\mathrm{Na}$ temperatura de $20^{\circ} \mathrm{C}$, o índice de velocidade de germinação foi maior no rolo de papel, diferindo estatisticamente dos demais substratos (Tabela 1); a $25^{\circ} \mathrm{C}$ não houve diferença significativa entre o rolo de papel, sobre papel e sobre areia. Os substratos rolo de papel e sobre areia proporcionaram maiores valores de velocidade de germinação na temperatura de $30^{\circ} \mathrm{C}$ e, na temperatura alternada de $20-30^{\circ} \mathrm{C}$ a maior velocidade foi obtida com o rolo de papel, diferindo estatisticamente dos demais substratos. O fato de o rolo de papel ter demonstrado vantagens em todas as temperaturas testadas pode ser atribuído a uma maior área de contato entre as sementes e o rolo, o que não ocorreu sobre papel, sobre e entre areia.

No substrato rolo de papel, nas temperaturas de 20, 25 e $20-30^{\circ} \mathrm{C}$, não houve diferença entre a velocidade de germinação, observando-se os maiores valores entre todos os tratamentos (Tabela 1); a temperatura de $25^{\circ} \mathrm{C}$ também foi a mais favorável nos substratos sobre papel e sobre areia, enquanto entre areia não houve diferença significativa nas temperaturas utilizadas, porém os valores de velocidade de germinação foram os mais baixos, comparados aos demais tratamentos. Em sementes de pinhão manso, MARTINS et al. (2008) verificaram que a temperatura alternada de $20-30^{\circ} \mathrm{C}$ no substrato rolo de papel foi a mais favorável à velocidade de germinação.

Os resultados do presente trabalho estão de acordo com BEWLEY \& BLACK (1994), os quais relataram que a temperatura exerce influência na velocidade e porcentagem de germinação. Diversos trabalhos têm evidenciado que a temperatura pode exercer efeitos positivos ou negativos na germinação de algumas sementes, conforme verificado em Brassica tournefortii Gouan., cuja temperatura ótima foi $12-20^{\circ} \mathrm{C}$ (CHAUHAN et al., 2006), enquanto, para Raphanus sativus L. var. oleiferus Metzg., a temperatura de $20-30^{\circ} \mathrm{C}$ é a mais recomendada (NERY et al., 2009). Em sementes de almeirão, a germinação foi drasticamente reduzida em temperaturas baixas $\left(10^{\circ} \mathrm{C}\right)$ e os maiores valores foram obtidos na temperatura de $20^{\circ} \mathrm{C}$, embora a $35^{\circ} \mathrm{C}$ tenha ocorrido uma boa porcentagem de germinação (PINTO JUNIOR et al., 2009). Temperaturas muito baixas ou altas poderão alterar tanto a velocidade quanto a porcentagem final de germinação, pois temperaturas baixas geralmente reduzem, enquanto as altas aumentam a velocidade de germinação, especialmente de sementes da família das cucurbitáceas (NASCIMENTO et al., 2011).

O rolo de papel proporcionou redução no tempo médio de germinação das sementes de kino, comparado aos demais; os substratos entre areia e sobre areia não diferiram entre si e, no substrato sobre papel, observou-se o maior tempo médio de germinação (Figura 1A), sendo que este também foi influenciado pela temperatura utilizada (Figura 1B), pois verificou-se que as sementes germinaram mais rápido nas temperaturas de 20 e $25^{\circ} \mathrm{C}$, proporcionando menor tempo médio de germinação. Em contrapartida, a temperatura de $30^{\circ} \mathrm{C}$ foi prejudicial às sementes, uma vez que foi responsável pelo maior tempo médio de germinação. A rapidez na germinação é muito importante, porque reduz o grau de exposição das sementes e das plântulas às intempéries, criando uma situação favorável para que não ocorram falhas no estande ou desuniformidade de plântulas, podendo prejudicar significativamente a produção final (NASCIMENTO et al., 2011).

No rolo de papel, observou-se que a germinação teve início no quinto dia após a instalação do teste nas temperaturas de 20,25 e $20-30^{\circ} \mathrm{C}$ e, no sexto dia, para a temperatura de $30^{\circ} \mathrm{C}$ (Figura 2A). A partir do oitavo e décimo dias, houve a estabilização da germinação nas temperaturas de 25 e $20-30^{\circ} \mathrm{C}$, respectivamente, atingindo valores acima de $80 \%$. Para as temperaturas de 20 e $30^{\circ} \mathrm{C}$, a estabilização da germinação ocorreu no nono e décimo dias, respectivamente, porém os valores não atingiram 62\%. CÍCERO (1986) relatou a importância da temperatura alternada, que possivelmente age sobre os tegumentos das sementes, tornando-os mais permeáveis à água e ao oxigênio e, provavelmente, influencia o equilíbrio entre as substâncias promotoras e inibidoras da germinação.

Com relação ao substrato sobre papel, a germinação iniciou-se no quinto dia para a temperatura de $20^{\circ} \mathrm{C}$; sexto dia, para as temperaturas de 25 e 20 $30^{\circ} \mathrm{C}$; e, no oitavo dia, para a temperatura de $30^{\circ} \mathrm{C}$ (Figura 2B). Não houve estabilização da germinação até o décimo sexto dia para as temperaturas utilizadas, com exceção da temperatura de $20^{\circ} \mathrm{C}$, cuja estabilização ocorreu no décimo segundo dia. Apenas na temperatura de $25^{\circ} \mathrm{C}$ os valores de germinação foram acima de $80 \%$, enquanto as temperaturas de 20 e $30^{\circ} \mathrm{C}$ afetaram negativamente as sementes de kino, não atingindo 40\% de germinação. 


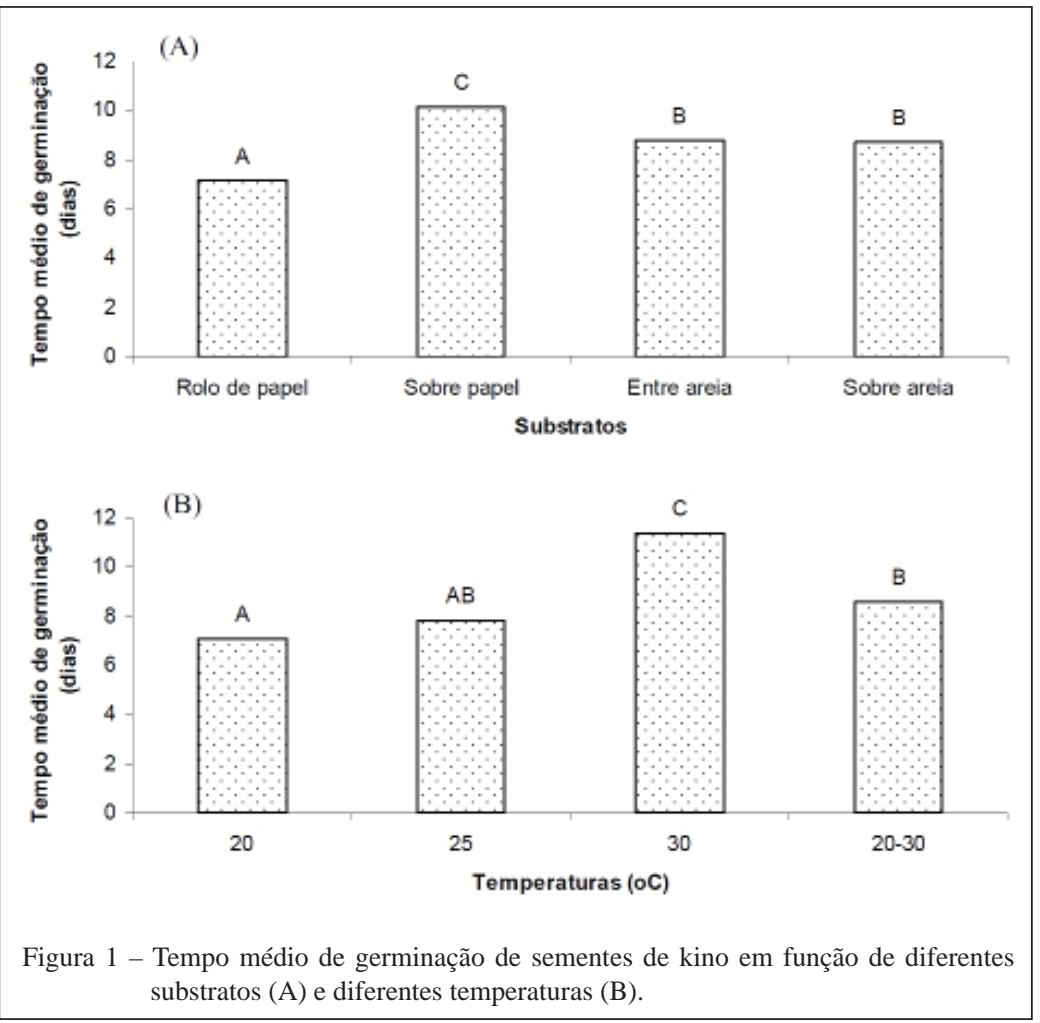

O substrato que mais afetou negativamente a germinação das sementes de kino foi entre areia, pois, independente da temperatura utilizada, os valores foram inferiores a $30 \%$ (Figura 2C); para as temperaturas de 20,25 e $30^{\circ} \mathrm{C}$, a germinação se iniciou no quinto dia e, para a temperatura alternada de $20-30^{\circ} \mathrm{C}$, foi no sexto dia, porém não houve estabilização da germinação até o décimo sexto dia após a instalação do teste em nenhuma das temperaturas utilizadas.

No substrato sobre areia, a germinação teve início no quinto dia nas temperaturas de 20, 25 e $20-30^{\circ} \mathrm{C}$ e, no sexto dia, a $30^{\circ} \mathrm{C}$ (Figura 2D), cuja estabilização da germinação foi no décimo dia na temperatura de $20^{\circ} \mathrm{C}$, porém os valores não atingiram $25 \%$. A temperatura de $25^{\circ} \mathrm{C}$ proporcionou valores acima de $80 \%$ de germinação, porém não houve a estabilização até o décimo sexto dia, fato que também foi observado nas temperaturas de 30 e 20-30 ${ }^{\circ} \mathrm{C}$, entretanto, nestas últimas a germinação não ultrapassou $65 \%$.

Um dos objetivos do teste de germinação é permitir que as sementes expressem o seu máximo potencial fisiológico, além de fornecer resultados rápidos. Nesse sentido, o substrato que melhor atendeu a essas expectativas foi o rolo de papel, no qual se verificou manutenção da umidade praticamente constante durante todo o teste de germinação, condição considerada essencial para uma boa germinação, aliada à vantagem da maior facilidade e rapidez de manuseio. Quando se utilizou o substrato sobre papel, ocorreu uma desidratação rápida, excessiva e desigual, sendo necessário reumedecê-lo durante o transcorrer do teste, fato que deve ser evitado sempre que possível, uma vez que isso pode causar variações adicionais nos resultados (BRASIL, 2009).

Ainda se observou que, quando se utilizou as temperaturas de 25 e $20-30^{\circ} \mathrm{C}$ no rolo de papel, a primeira contagem pode ser feita no quinto dia após a instalação do teste, momento em que se verificou, aproximadamente $30 \%$ de germinação das sementes de kino e a contagem final no décimo dia, quando houve estabilização da germinação (Figura 2A).

\section{CONCLUSÃO}

O teste de germinação em sementes de kino deve ser realizado em rolo de papel, na temperatura constante de $25^{\circ} \mathrm{C}$ ou alternada de $20-30^{\circ} \mathrm{C}$, com a contagem inicial e final no quinto e décimo dia, respectivamente. 


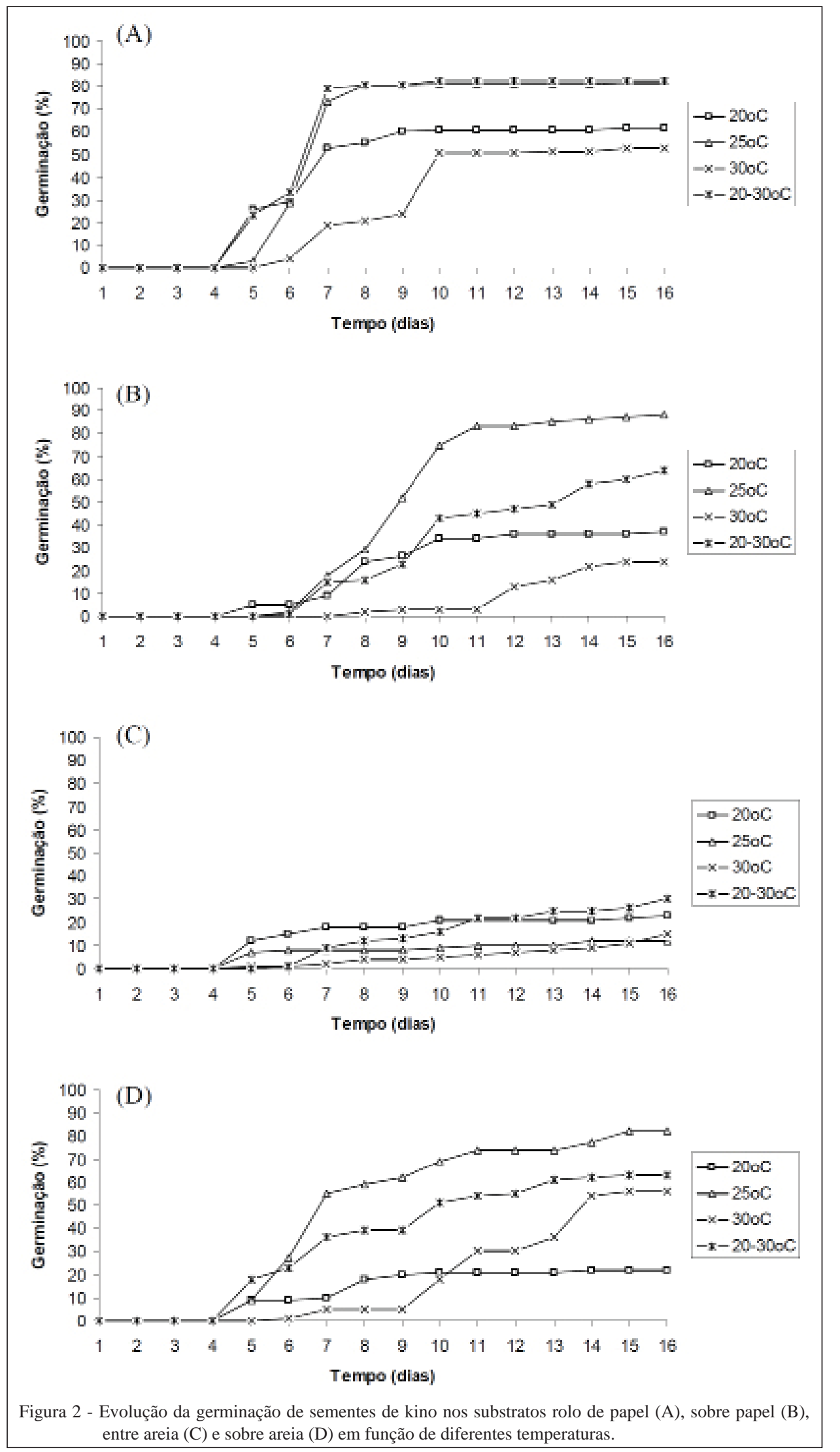

Ciência Rural, v.44, n.2, fev, 2014. 


\section{REFERÊNCIAS}

ALVES, C.Z. et al. Adequação da metodologia para o teste de germinação em sementes de pitaia vermelha. Ciência Rural, v.41, n.5, p.779-784, 2011. Disponível em: <http://www.scielo. br/scielo.php?pid=S0103-84782011000500007\&script $=$ sci arttext>. Acesso em: 20 dez. 2012. doi: 10.1590/S010384782011005000051 .

BENZIONI, A. et al. Effect of sowing dates, temperatures on germination, flowering and yield of Cucumis metuliferus. HortScience, v.26, n.8, p.1051-1053, 1991.

BENZIONI, A. Kiwano (Cucumis metuliferus). In: JANICK, J.; SIMON, J.E. New crops. New York: Purdue University, 1997. Disponível em: <www.hort.purdue.edu/newcrop/cropfactsheets/ kiwano.html>. Acesso em: 25 ago. 2012.

BEWLEY, J.D.; BLACK, M. Seeds: physiology of development and germination. New York and London: Plenum, 1994. 445p.

BRASIL. Ministério da Agricultura, Pecuária e Abastecimento. Regras para análise de sementes. Secretaria de Defesa Agropecuária. Brasília: MAPA/ACS, 2009. 395p.

CARNEIRO, J.W.P.; GUEDES, T.A. Influência do contato das sementes de Stevia (Stevia rebaudiana (Bert.) Bertoni.) no substrato avaliada pela função da Weibull. Revista Brasileira de Sementes, v.4, n.1, p.65-68, 1992.

CARVALHO, N.M.; NAKAGAWA, J. Sementes: ciência, tecnologia e produção. 5.ed. Jaboticabal: FUNEP, 2012. 590p.

CHAUHAN, V.S. et al. African mustard (Brassica tournefortii) germination in sourthern Australia. Weed Science, v.54, n.5, p.891-897, 2006.

CÍCERO, S.M. Dormência de sementes. In: SEMANA DE ATUALIZAÇÃO EM PRODUÇÃO DE SEMENTES, 1986, Pircicaba, SP. Anais... Piracicaba: FEALQ, 1986. p.41-74.

DE LA ROSA-IBARRA, M. et al. Germination and methods to break seed dormancy of Brassica juncea and Brassica campestris. Phyton-International Journal of Experimental Botany, v.66, p.93-96, 2000.
FUNDACIÓN EROSKI. Kiwano. Disponível em: <www.frutas. consumer.es/documentos/tropicales/kiwano/receta.php>. Acesso em: 28 ago. 2012.

LABOURIAU, L.G. A germinação das sementes. Washington: Secretaria da OEA, 1983. 173p.

MAGUIRE, J.D. Speed of germination aid in selection and evaluation for seeding emergence and vigor. Crop Science, v.2, n.2, p.76-177, 1962

MARSH, D.B. Evaluation of Cucumis metuliferus as a specialty crop for Missouri. In: JANICK, J.; SIMON, J.E. New crops. New York: Purdue University, 1993. Disponível em: <www.hort. purdue.edu/newcrop/proceedings1993/V2-558.html>. Acesso em: 01 set. 2012.

MARTINS, C.C. et al. Temperatura e substrato para o teste de germinação de sementes de pinhão-manso. Ciência e Agrotecnologia, v.32, n.3, p.863-868, 2008.

NASCIMENTO, W.M. et al. Qualidade fisiológica da semente e estabelecimento de plantas de hortaliças no campo. In: Curso sobre Tecnologia de Produção de Sementes de Hortaliças, 11. Porto Alegre/RS: Embrapa Hortaliças, 2011. CD-ROM.

NERY, M.C. et al. Adequação do teste de germinação para sementes de nabo forrageiro. Revista Brasileira de Sementes, v.31, n.2, p.177-187, 2009. Disponível em: <http://www.scielo.br/scielo. php?script=sci_arttext\&pid=S0101-31222009000200021\&lng $=$ p t\&nrm=iso\&tlng=pt>. Acesso em: 18 nov. 2012. doi: 10.1590/ S0101-31222009000200021

OLIVEIRA JUNIOR, R.S.; DELISTOIANOV, F. Profundidade de semeadura e métodos de quebra de dormência afetando a germinação e emergência de Desmodium purpureum (Mill.) Fawc. Et Rend. (Leguminosae-Papilionoideae). Revista Brasileira de Botânica, v.19, n.2, p.221-225, 1996.

PINTO JUNIOR, A.S. et al. Germinação de sementes de almeirão sob temperaturas adversas. Horticultura Brasileira, v.27, n.2, p.1232-1238, 2009. (Supl. - CD Rom).

POPINIGIS, F. Fisiologia da semente. Brasília: Agiplan, 1985. 289p. 